\title{
Scope of Energy Conservation in Pumping System
}

\author{
Hamender Jain, CEng, CEA, CEM \\ Bechtel Corporation
}

\begin{abstract}
Pumps consume about 22\% of the world's total energy generated, out of which $16 \%$ is consumed by centrifugal pumps and $6 \%$ by rotodynamic pumps. According to the American Hydraulics Institute, 30\% of the total electrical energy consumed by pumping systems can be conserved either by designing highly efficient systems or by using appropriate pumps. As a result, the primary focus of global energy policy makers is to enhance energy efficiency in pumping systems. This paper aims to highlight the areas that need to be address in order to increase the pumping system efficiency. It is evident from studies that about $30 \%$ to $50 \%$ of the energy consumed by pumping systems could be saved through piping system components or control changes.
\end{abstract}

Key words: Industrial Energy, Energy Conservation, Pumping System, Energy Efficiency

\section{Introduction}

Energy is one of the major inputs for the economic development of the country. The economic growth has led to increase in demand of energy. Over the years, increased usage of conventional sources for the generation of electrical energy has not only depleted the conventional energy resources but is also causing drastic climatic changes. Furthermore, this is also resulting in an energy crisis which results in increase in cost of energy as well as a fluctuation in its price. In such scenario, efficient use of energy resources and their conservation gain tremendous significance and is essential for curtailment of wasteful consumption and sustainable development. Enhancing energy efficiency is also important to reduce carbon emission and combat against the threat of climate change.

World's energy consumption is expected to increase nearly by $48 \%$ from 2018 to 2050 [1]. Global energy usage from 620 quad BTU in 2018 is estimated to reach 910 quad BTU in 2050 as illustrated in Fig. 1. In the next 22 years (by 2050), the industrial energy consumption alone is expected to reach 22860 TW (1.4\% per year) $[1,2]$. Therefore, this concern must be addressed by the researchers and international society to overcome the energy deficit in the future and to identify the energy saving potential.

\section{Overview of Pumping System Energy Consumption}

As national and international markets continue to become more competitive, organizations continually seeking cost savings opportunities that will provide more profitability. One of the areas which gain high attention is plant equipment operations as it has high potential of cost savings, especially minimizing energy consumption and plant downtime. By minimizing energy intensity without affecting the output of specific product, process or area of production or consumption, overall energy efficiency of plant would be achieved.

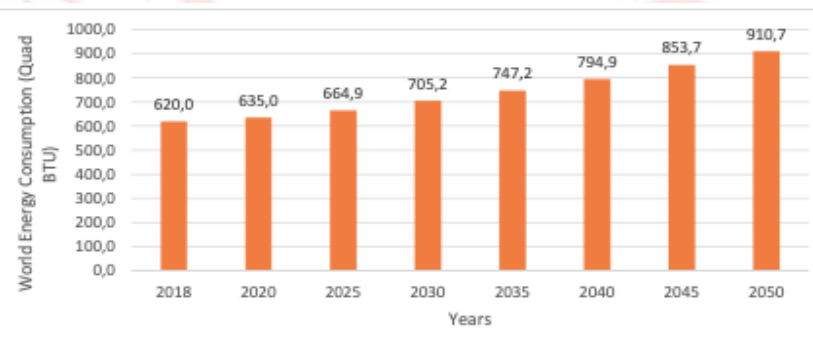

Figure 1: Global Energy Consumption from 2018 to 2050

According to the International Energy Agency [3] electric motors consume $46 \%$ of the electricity generated in the world.

As per the report made by the European Commission [4], the pumping system accounts for nearly $22 \%$ of the energy supplied as shown in Fig. 2. Therefore, it is worthwhile to investigate the energy saving opportunities and methodology to enhance energy efficiency in the pumping system.

Energy cannot be transformed from one useful form to the other without losses [5]. Losses incurred at each component of the pumping system. This was studied by U.S. Department of Energy [6] in Table 1. From table 1, it shows that the maximum possible losses in the pumping system are due to inefficient piping system design, contributing to about 40 $50 \%$ of losses. The efficiency of pumps is $85-90 \%$ [7]; electric motors (Eff1) is more than 90\% [8], and VFDs is around 95-98\% [9] respectively.

Life cost cycle of medium sized industrial pump indicates that energy consumption is the main contributor of larger cost as compared to other costs like initial purchase, maintenance etc. especially if pumps run more than 2000 hours per year as shown in below figure 3 . 


\section{Yinternational Research Journal}

p-ISSN 2202-2821 e-ISSN 1839-6518 (Australian ISSN Agency)

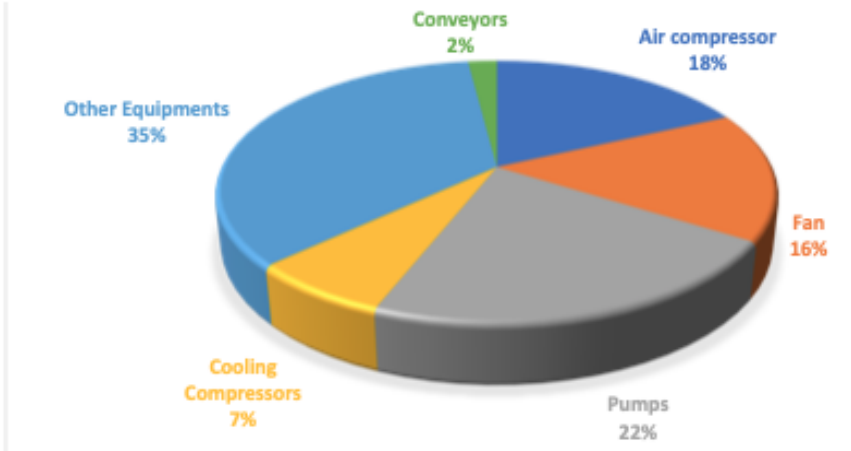

Figure 2: Energy Consumption in Different Application

\begin{tabular}{clcc}
\hline S.No & Component in Pumping System & Efficiency (\%) & Losses (\%) \\
\hline 1 & Piping system & $50-60$ & $40-50$ \\
2 & Pump & $85-90$ & $10-15$ \\
3 & Coupling & $\sim 99$ & $\sim 1$ \\
4 & Motor & $>90$ & $<10$ \\
5 & VFD & $95-98$ & $2-5$ \\
\hline Table I: Lasses in Pumping System & &
\end{tabular}

The energy and materials used by a system depend on the design of the pump, the design of system, installation, and the way system will operate. These factors are interdependent and must be carefully matched to each other so that throughout the working life of pumping system, energy and maintenance costs reduced.

Typical life-cycle costs for a medium-sized industrial pump system

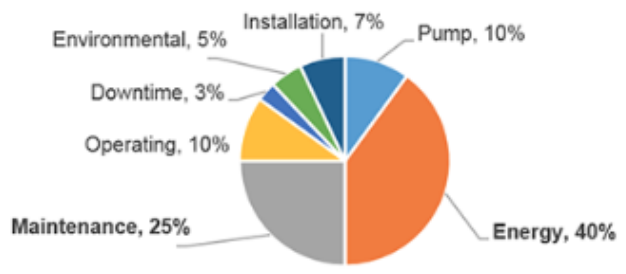
Figure 3: LCC Analysis of Pumping System (source: Pump Life Cycle Cost: A Guide to LCC Analysis for

Operating and process parameter is other factor which play important role in energy consumption in pumping system. Refer to below equation,

- $\mathrm{T}_{\text {tot }}$ is the number of operating hours,

- $\quad \mathrm{i}$ is the consecutive number and

- $\mathrm{N}$ is the total number of flow rate interval.

- $\mathrm{Q}$ demand and $\mathrm{H}$ demand refer to flow and respective head requirement during different operating conditions.

From the below equation 1 [10], it is clear that energy consumption by pumping system over a certain time period not only depends upon the efficiency of individual components at nominal operating condition but also range of flow rate demanded, flow time profile of respective

\section{Vol. 10 No. 022020}

\section{1}

application, and efficiencies of individual components over whole range of operating condition (part load and overload conditions).

$$
E_{\text {consumption }}=T_{\text {tot }} \sum_{i=1}^{i=N}\left(\frac{\Delta t}{T_{\text {tot }}}\right)_{\mathrm{i}} \times\left(\frac{\rho \cdot g \cdot \mathrm{Q}_{\text {demand. }} \mathrm{H}_{\text {demand }}}{\eta_{\text {pump }} \eta_{\text {drive }}} \times \frac{\mathrm{H}_{\text {pump }}}{\mathrm{H}_{\text {demand }}}\right)
$$

Equation 1: Energy Consumption at varying flow rate and head

\section{Energy Efficiency Enhancement Opportunities}

The Opportunities for improving the energy efficiency in a pumping system are broadly classified into three distinct categories: Detailed design, Operation, and Maintenance (see Fig. 4). Each category contributes on its own in energy conservation during the life cycle of pumping system.

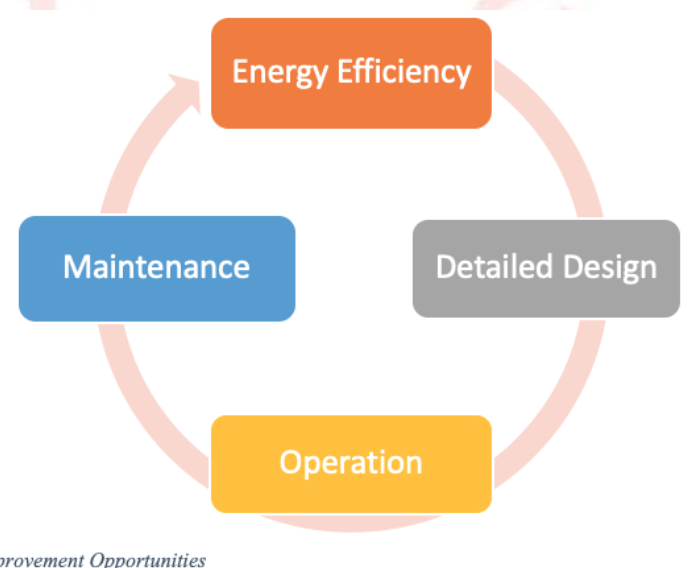

Figure 4: Energy Improvement Opportunities

Detailed design focuses on component selection (pump, motor and coupling), system design (pipe size, piping component and valves selection) and control method. Operation focuses on running the pumping system effectively and efficiently to minimize the energy consumption. Maintenance focuses on preventive maintenance to increase the life of pumping system components. As shown in figure 3, maintenance contributes $25 \%$ cost of pumping system life cost cycle.

An energy efficient pumping system meets the requirements of flow rate and head with minimum energy consumption. Pumps from a wide range of types and models are selected based on their ability to meet system requirements. The other factors like duty point, net positive suction head available and required, components operating life and maintenance procedure are also elements to be considered in the selection process.

Pumping system having different flow and pressure requirement at different point of time have efficiency varies 


\section{Yinternational Research Journal}

p-ISSN 2202-2821 e-ISSN 1839-6518 (Australian ISSN Agency)

with flow and pressure, and at one particular flow rate it is highest. This point is called best efficiency point. At this point, pump power input is equal to 1 and the pump efficiency is maximum. As per international code and standards, selection of pump shall be such that it should always be operated $\pm 20 \%$ of best efficiency point in order to obtain maximum efficiency.

Operating on or as close to the pumps BEP not only has energy consumption advantages (Cost per unit volume) but also have additional benefits like increased bearing and seals life, noise, vibration within the limits and increased the overall mean time before failure as shown in Figure 5. All the points on the right or left of the BEP have a lower efficiency. The figure 5 also indicates the risk and reliability concerns related to bad pump selection and inaccurate system design.

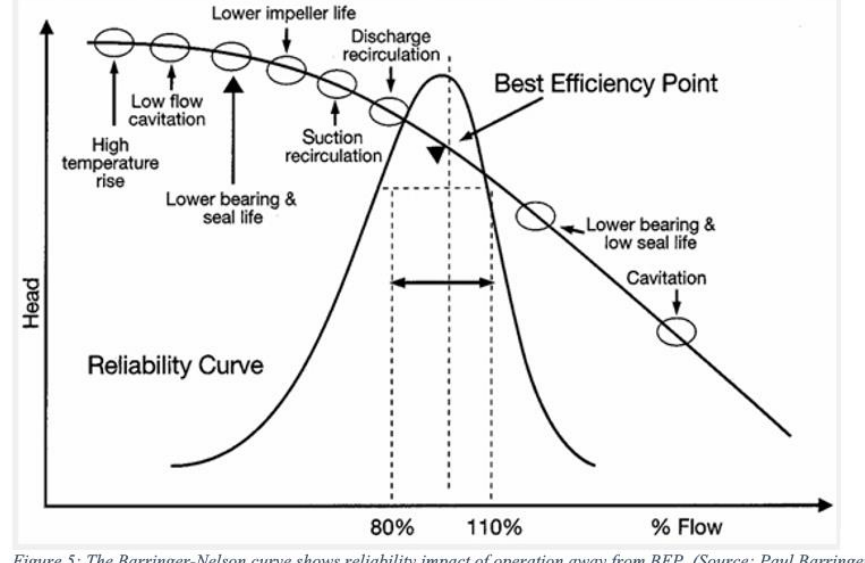

As shown in section II equation, energy efficiency in pumping system also depends on the electric motor efficiency. Selection of type of motor from large product range should be reliable for pumping system and should have high efficiency.

Energy efficient motor are the one which have improved design over standard motor specifically designed to increase operational efficiency. This is achieved by reducing intrinsic motor losses, use of lower-loss silicon steel, a longer core (to increase active material), thicker wires (to reduce resistance), thinner laminations, reduced air gap between stator and rotor, use of copper instead of aluminum bars in the rotor, superior quality bearings and a small size of fan.

Energy efficient motors operates normally with efficiencies 3 to 4 percent more than standard motors. The power factor of energy efficient motors is higher than the standard motor. These motors are designed to operate in load $75 \%$ to $100 \%$ of rated capacity without losing efficiency. This result in major benefits in varying load applications. The other benefit of energy efficient motors is lower operating temperature, greater

\section{Vol. 10 No. 022020}

82801002202001

ability to accelerate at higher inertia load, less affected by supply voltage fluctuations and lower noise level.

The choice of pump for a given application depends largely on how the pump head-flow characteristics match the system requirement downstream of the pump. As specified above in section II, the duration of operation at the different duty points (part load and overload conditions) should be considered in selecting the most efficient pump for the specific requirements.

Other factor which are responsible for lowering the system efficiency and increasing energy consumptions is adding more safety margins to the calculated system curve to ensure that a sufficiently large pump is selected for a particular system, this leads to actual system curve different than actual required hence pump will operate at a flow and head different to that expected. As a result, the system curve shifts to the left or right and intersects the pump curve at another point. If this shift is within the range of best efficiency point than this should not be a problem otherwise pump efficiency reduces. Further, this results in installing a pump, which will operate at an excessive flow rate or in a throttled condition which increases energy usage and reduces pump life.

Proper system design considers the interaction between the pump and the rest of the system. The pressure drop of the piping system must be calculated in order to determine required pump performance. This applies to both simple piping systems as well as branched piping systems.

During system design, selection of pipe diameter and material (based on fluid properties) has direct impact on pressure loss in pumping system which ultimately decide pump selection and energy efficiency. Although there are other factors such as pipe length, type of fittings and valves etc., which contributor to pressure loss but the considerable change is observed by change in pipe length, diameter and material.

The general formula which expresses the piping loss in incompressible fluids is Darcy-Weisbach formula:

$$
h_{f}=\frac{64 \mathrm{fL} Q^{2}}{\pi^{2} d^{5} 2 g}
$$

\section{Equation 2: Darcy Weisbach formula to calculate pressure drop}

By analyzing the Darcy-Weisbach, it is possible to notice that, once the flow is fixed, the pressure losses depend by the following parameters: Pipe diameter, Pipe Length, Friction coefficient and Reynold number.

As per the literature, considerable energy savings can be accomplished by controlling the speed of the pumping system 


\section{Yinternational Research Journal}

p-ISSN 2202-2821 e-ISSN 1839-6518 (Australian ISSN Agency)

using Variable Frequency Drives (VFDs) as compared to other methods specified in table 2 .

\begin{tabular}{|l|l|l|l|}
\hline Parameter & $\begin{array}{l}\text { Change control } \\
\text { valve }\end{array}$ & Trim impeller & VFD \\
\hline Impeller diameter & $430 \mathrm{~mm}$ & $375 \mathrm{~mm}$ & $430 \mathrm{~mm}$ \\
\hline Pump head & $71.7 \mathrm{~m}$ & $42 \mathrm{~m}$ & $34.5 \mathrm{~m}$ \\
\hline Pump efficiency & $75.1 \%$ & $72.1 \%$ & $77 \%$ \\
\hline Rate of flow & $80 \mathrm{~m}^{3} / \mathrm{hr}$ & $80 \mathrm{~m}^{3} / \mathrm{hr}$ & $80 \mathrm{~m}^{3} / \mathrm{hr}$ \\
\hline Power consumed & $23.1 \mathrm{~kW}$ & $14 \mathrm{~kW}$ & $11.6 \mathrm{~kW}$ \\
\hline
\end{tabular}

Table 2: Comparison of different energy conservation options in Pumps (adopted from US DOE 2001)

Figure 6 shows the typical load profile of a pump in 24 hours as an example. This pump application needs to cover several duty points, of which the largest flow and/or head will determine the rated duty for the pump. Instead of size the pump at full $100 \%$ capacity and highest pressure, carefully consider the duration of operation at the individual duty points ( $Q_{\text {demand }}$ and Hdemand) to properly select the number of pumps in the installation. Using System load profiles and sizing pumps accordingly make the system more energy efficient.

Taking into the account of flow-time profile, consumption of electric energy by pumping system over a certain period of operation not only determined by the efficiency value of its component (pump and motor) at their respective nominal operating condition but also determined by efficiency value of component at part load condition, flow and head demand of system and range of flow demanded at particular time frame.

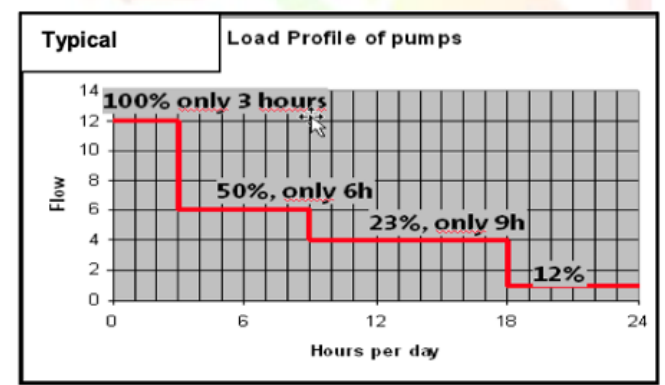

Figure 6: Typical load profile of Pump showing different system requirement at different time

\section{System design indicate potential improvement in energy efficiency}

\begin{tabular}{|l|l|l|}
\hline System Design & $\begin{array}{l}\text { Likely } \\
\text { Reason }\end{array}$ & $\begin{array}{l}\text { Best } \\
\text { Solutions }\end{array}$ \\
\hline $\begin{array}{l}\text { Pumping system } \\
\text { controlled by throttle } \\
\text { valve }\end{array}$ & $\begin{array}{l}\text { Oversized } \\
\text { Pump }\end{array}$ & $\begin{array}{l}\text { Trim } \\
\text { Variable speed drive, } \\
\text { Two speed drive }\end{array}$ \\
\hline $\begin{array}{l}\text { Pumping system } \\
\text { having bypass line } \\
\text { open (partially or } \\
\text { fully) }\end{array}$ & $\begin{array}{l}\text { Oversized } \\
\text { Pump }\end{array}$ & $\begin{array}{l}\text { Trim } \\
\text { Variable speed drive, } \\
\text { Two speed drive }\end{array}$ \\
\hline $\begin{array}{l}\text { Multiple parallel } \\
\text { Tumps not }\end{array}$ & Pumper, \\
\hline
\end{tabular}

www.irj.iars.info

www.researth.iars.info/index.php/curie
Vol. 10 No. 022020

82801002202001

\begin{tabular}{|l|l|lr|}
\hline $\begin{array}{l}\text { pumps always } \\
\text { running }\end{array}$ & $\begin{array}{l}\text { monitored } \\
\text { or } \\
\text { controlled }\end{array}$ & pumping system \\
\hline $\begin{array}{l}\text { Constant pump } \\
\text { operation in batch }\end{array}$ & $\begin{array}{l}\text { Wrong } \\
\text { System } \\
\text { Design }\end{array}$ & $\begin{array}{l}\text { On-off } \\
\text { method }\end{array}$ \\
\hline $\begin{array}{l}\text { High Maintenance } \\
\text { cost (Bearing and } \\
\text { Seals) }\end{array}$ & $\begin{array}{l}\text { Pump } \\
\text { operated far } \\
\text { from Best } \\
\text { Efficiency } \\
\text { Point }\end{array}$ & $\begin{array}{l}\text { Match } \\
\text { capacity with system }\end{array}$ \\
\hline
\end{tabular}

Table 3: System design indicate potential improvement from energy conservation point of view [11]

\section{Conclusion}

This review has shown that pumping system consumes considerable amount of energy during its life span. Industrial growth and reduction in resources for producing energy drives the need of alternative ways through which reduction in energy consumption can be achieved. Changing government regulations and strict environment laws makes it more challenging. One of the easiest alternative way is to eliminate the energy waste from existing equipment to make them more efficient. This will not only improve the efficiency of plant but reduce energy consumption and provide competitive advantage to industry.

To summarize, a number of brief points to consider:

- $\quad$ Select the pump ensuring best efficiency at different operating condition of system requirement rather than design at worst condition.

- $\quad$ Select energy efficient motor and variable frequency drive where appropriate.

- $\quad$ Optimize the pipe sizing, pipe routing and piping component.

- Avoid throttling control wherever possible.

- Design separately for high pressure and low-pressure system

- Adopt extended product approach

- Analyze life cycle cost of pump at the beginning rather than at later stage.

- Emphasis on unit cost i.e. $\mathrm{kWh} / \mathrm{m} 3$

- $\quad$ Replace old pumps timely 
- Focus on preventive maintenance as per manufacturer's guideline.

- Collect and analyze the operating data regularly and take corrective actions to ensure pumping system optimization.

- Consult with specialists and regulatory bodies in the industry to assist where necessary.

\section{References}

[1]. U.S. Energy Information Administration. International energy outlook 2019

[2]. D Abdelaziz EA, Saidur R, Mekhilef S. ,"A review on energy saving strategies in industrial sector." Renew Sustain Energy Rev 2011

[3]. Waide P, Brunner CU. Energy-efficiency policy opportunities for electric motor-driven systems international energy agency energy efficiency series; 2011.

[4]. European Commission. Study on improving the energy efficiency of pumps; 2001.

[5]. Tamminen J, Kosonen A, Ahonen T, Ahola J, Immonen $\mathrm{P}$, Muetze A, et al. Component selection tool to maximize overall energy conversion efficiency in a pumping system. In: 2013 15th Eur. conf. power electron. appl. EPE 2013. IEEE; 2013, p. $1-9$.

[6]. U.S. Department of Energy. Improving motor and drive system performance; 2008.

[7]. Kaya D, Yagmur EA, Yigit KS, Kilic FC, Eren AS, Celik C. Energy efficiency in pumps. Energy Convers Manage 2008;49:1662-73. http://dx.doi.org/ 10.1016/j.enconman.2007.11.010.

[8]. Lu S-M. A review of high-efficiency motors: specification, policy, and technology. Renew Sustain Energy Rev 2016;59:1-12. http://dx.doi.org/ 10.1016/j.rser.2015.12.360.

[9]. Aranto N. Competitor comparison: Variable speed drives in pumping applications; 2008.

[10]. B Stoffel. Assessing the Energy Efficiency of Pumps and Pump Units: Background and Methodology

[11]. Bureau of Energy Efficiency (BEE), India $<$ https://beeindia.gov.in/> 